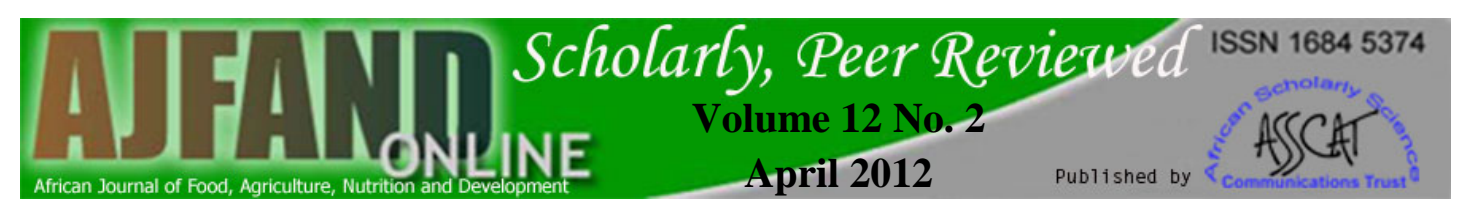

\title{
CONSUMPTION OF FRUITS AMONG STUDENTS: A CASE OF A PUBLIC UNIVERSITY IN GHANA
}

\author{
Mintah $\mathrm{BK}^{1^{*}}$, Eliason $\mathrm{AE}^{2}$, Nsiah $\mathrm{M}^{3}$, Baah $\mathrm{EM}^{3}$, Hagan $\mathrm{E}^{3}$ and DB Ofosu ${ }^{1}$
}

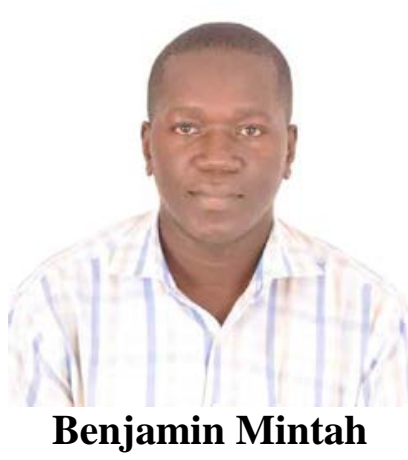

*Corresponding author Email: bkmintah@ug.edu.gh

${ }^{1}$ ICD-UGL Food Safety and Nutrition Training Centre, Department of Nutrition and Food Science, University of Ghana, Box LG 134, Legon-Accra, Ghana.

${ }^{2}$ Public Health and Allied Science Faculty, Catholic University College of Ghana, Sunyani, Ghana.

${ }^{3}$ School of Applied Science, Takoradi Polytechnic, Box 256, Takoradi, Ghana. 


\section{ABSTRACT}

Despite the enormous health and nutritional benefits that could be derived from the consumption of fruits, studies have shown that most adolescents and adults do not consume fruits as per the recommended daily intake. This study aimed at identifying the factors that hamper the consumption of fruits among university students. Four hundred and fifty-six $(n=456)$ out of a total population of nine thousand $(\mathrm{N}=9000)$ undergraduate students were considered for the study. A pre-tested structured questionnaire was used to solicit answers to questions on: fruit intake and preferences, perception on fruit consumption, fruit availability, and factors that hamper students' fruit intake. Descriptive statistical techniques (frequency counts, percentage, mean and standard deviations) as well as inferential tools (one-sample T-test, Pearson product-moment correlation, Chi-square one variable test, and Binomial test) were used in the data analysis, and statistical significance determined at the 5\% level $(\mathrm{P} \leq 0.05)$. Major findings from the study were that, students $(65 \%)$, against expectation, do not eat the recommended serving of fruits in a day $(\mathrm{P}<0.05)$, whereas approximately 6\% $(\mathrm{P}<0.05)$ do not eat fruits at all, although their perception on the consumption of fruits was good $(\mathrm{P}<0.05)$. Out of nine fruit types, that were readily available on the market for the subjects, pear (Pyrus communis) was the most preferred by students $(\overline{\mathrm{x}}=3.37, \mathrm{P}<0.05)$; whereas orange (Citrus sinensis) was the least preferred $(\overline{\mathrm{x}}=2.31, \mathrm{P}<0.05)$. A weak positive correlation, which was statistically significant $(r=0.13, \mathrm{P}<0.05)$, was observed for students' fruit and fruitfibre intake with respect to tangerine (Citrus reticulata). Also, a weak negative relationship, which was statistically significant $(r=-0.14, \mathrm{P}<0.05)$, was observed for the intake of oranges (Citrus sinensis) and its fibrous part. Variables such as taste, time-wasting, religious belief, knowledge, ill-health, and proximity did not significantly $(\mathrm{P}>0.05)$ influence the intake of fruits by the respondents $(\overline{\mathrm{x}}<2.50$, $\mathrm{P}>0.05)$. Price scores $(\overline{\mathrm{x}}=3.21)$ as well as satiety scores $(\overline{\mathrm{x}}=3.32)$ were the significant variables found to hinder students' fruit intake $(\mathrm{P}<0.05)$. Strategies to increase intake of fruits, should give more attention to the price and satiety variables.

Key words: fruit-consumption, perception, preference, factors, students 


\section{INTRODUCTION}

The term fruit has different meanings depending on the context in which it is used. For instance, in botany, a fruit is a part of a flowering plant that derives from specific tissues of the flower, mainly one or more ovaries [1]. Fruits in the botanical context also include many structures that are not commonly called fruits, for example: wheat grains, corn kennels, bean pods, and tomatoes. In a broader context, fruit is a structure of a plant that contains its seeds, or is the means by which many plants disseminate seeds [2, 3].

For the purpose of this study, the term fruit refers to the meaning as used informally by consumers. A fruit normally means the fleshy seed-associated structures of certain plants that are sweet and edible in the raw state such as apples, oranges, grapes, strawberries, juniper berries, and bananas; or similar-looking structures in other plants, even if they are non-edible or non-sweet in the raw state, such as lemons and olives $[1,3]$. The seed-associated structures that do not fit these informal definitions are usually called by other names, such as vegetables, pods, nuts, ears and cones [1, 3].

Fruits have provided various health benefits in the human diet. Several epidemiological studies have shown a strong relationship between high intake of fruits and reduced risk of cancer, cardiovascular disease particularly coronary heart disease, stroke, Alzheimer disease, and cataracts [4,5]. This is because fruits (as well as vegetables) are rich in dietary nutrients such as potassium, antioxidants and folic acid $[5,6,7]$. Diets that include a sufficient amount of potassium from fruits help reduce the chance of developing kidney stones and may help reduce the effect of bone-loss [8]. Fruits are also low in calories which would help lower calorie intake as part of a weight loss diet [8]. Apart from having the ability to reduce the chance of developing type-two diabetes, fruits play a positive role in the proper functioning of the brain by stimulating memory recall [9]. Fruits also supply the human body with fibre needed for a healthy digestive system $[8,10]$. Despite the enormous benefits one derives from eating fruits, not much work has been devoted to study the consumption of fruits among students (and other groups) in Ghana [11]. Lack of good eating habits amongst students at the tertiary level despite the degree of information on the health benefits of fruits is an issue of concern since it can pose a lot of health threats in the long-term. It is therefore imperative that a study on the consumption of fruits among students is conducted. A number of studies have identified the eating habits and food preferences of students, but the practical approach(es)/strategies to help students include fruits in their daily meals remain unaddressed [12, 13, 14, 15]. Some studies have also examined the food choices of students and the researchers reported that there was a high preference for fizzy drinks (and snack food such as cakes and biscuits) than fruits [12, 13]. While such studies have explored food preferences in general at schools, the factors that could negatively influence the consumption of fruits among students have rarely been considered. To derive the nutritional benefits from the consumption of fruits, 2-4 servings of fruits per day is recommended [16, 17]. Countries like United States and Denmark have even recommended five or six servings respectively in a day $[18,19]$. A serving of fruit is

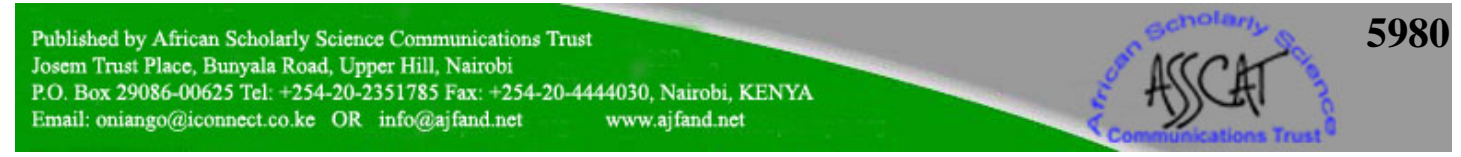


equivalent to $80 \mathrm{~g}$ or one medium apple, orange, banana and other similar sized fruits; half grapefruit or avocado or a slice of large fruit such as melon or pine apple [20].

Studies conducted in Europe (Belgium, Denmark, Estonia, Finland, Germany, Greece, Lithuania, Norway, Spain, Sweden and the United Kingdom) have shown that, consumption of fruits was common among those with higher education qualification [21]. The situation in Ghana might be different as some studies have reported that most Ghanaians in general do not consume fruits as recommended per day [11, 22]. There is also, supposedly, the general perception that students in Ghana, particularly those from higher education backgrounds do not consume fruits and if they do, it is much less than recommended per day. This study, therefore, sought to investigate the factors that negatively affect the consumption of fruits among university students. Educational, personal/religious values, food habit, health, time involved in eating fruits (time-wasting) and economic factors were some of the major factors considered for the study [23, 24, 25]. The study also sought answers to the research questions: (2) Do students eat the required quantity of fruits each day? (3) What is the perception of students on the consumption of fruits? (4) What kinds of fruits are available on the market for students? (5) What type of fruit(s) do students normally like consuming? (6) What is the association between students' fruit and fruit-fibre intake?

\section{SUBJECTS AND METHODS}

A research population of nine thousand (9000) consisting of all regular undergraduate students (aged 18-29 years) of one of the urban public universities in Ghana were considered. The university had seven (7) schools (Arts, Education, Social Science, Biological Science, Physical Science, Agriculture, and Business), and majority (95\%) of the students were accommodated in self catering halls of residence and hostels on the university campus. Self catering halls/hostels are residences in which students are responsible for providing and/or cooking their own food. Kitchens are provided in which students may prepare their own food, or meals may be bought from food outlets. For fair representation of the students from the various faculties of the university, stratified and simple random sampling techniques were used to select $5.3 \%$ of the total population resulting in a sample size of 477 of which 456 retrieved instruments were included for analysis [26].

A study of the population of 9000 requires a sample size of $4.10 \%$ of the population to make it representative [26]. In this study, $5.3 \%$ of the population was selected in anticipation that about $20 \%$ of the respondents would unlikely return or complete the research instrument. A pre-tested structured questionnaire (research instrument), which had five sections was used to collect data on the subjects (students/ respondents). The first part of the questionnaire covered the socio-demographic and economic data of the respondents. Also, information was gathered on the cost of meals per plate prepared by participants or bought from food outlets. A plate of food constituted a serving of carbohydrate, protein, vegetable and oil. Information on the cost of fruits per serving was also gathered. The second part was used to determine whether students ate the required quantity of fruit in a day. The third part which

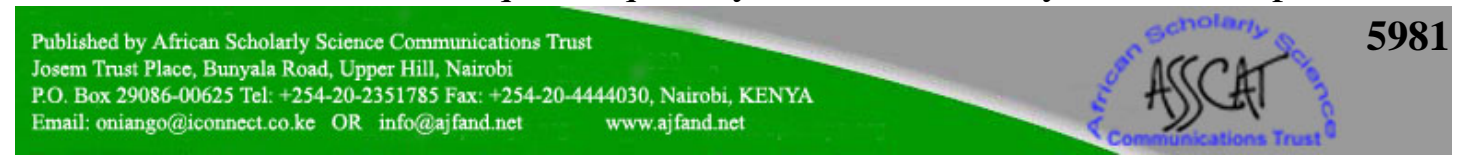


required grading of responses on a likert scale of 4-1(strongly agree - strongly disagree) covered the perception of the students on fruit consumption. Respondents were made to indicate the kinds of fruits available to them on campus in part four of the questionnaire. Also in part four of the research instrument, subjects were made to indicate how much they liked eating fruits on a scale of 4-1 (like very much - dislike very much). Furthermore, subjects were made to indicate in part four of the research instrument and on same scale of 4-1, how much they liked eating the fibrous chewyparts of those fruits that have reasonably high fibre content (orange, pine apple, and tangerine). Part five covered the factors that affected their fruit intake. Permission was sought from the administration of the University before the study was conducted, and participants who took part in the study participated voluntarily without any tangible motivation or reward. Participants were, however, assured that data they provided would be used for the purpose of the research only. Data were collected within four days with the help of 10 trained research assistants.

The study was conducted within the months of March and April, the time at which most fruits were in season in Ghana.

\section{DATA ANALYSIS}

Using the Statistical Package for Social Sciences (SPSS - version 16.0), percentage values were computed for data on the economic characteristics of participants; whereas mean scores were computed for cost of food/meals on the market. Also, percentage, mean and standard deviation (SD) values were computed for the data obtained for research questions 1, 3, 5 and 6 (major factors that hinder students' fruit intake, perception of students on eating fruits, students' fruit preferences, and the association between fruit and fruit-fibre intake, respectively); whereas frequency as well as percentage values were computed for research questions 2 and 4 (daily intake of fruits and fruit types available to students on the market, respectively). In addition, one sample T-test analyses were done to compare the mean scores obtained for research questions 1,3 and 5 to the population mean; and correlation co-efficient $(r)$ values were computed to determine the association between fruit and fruit-fibre intake by the respondents. Variations in participants' responses on daily stipend for meals and the number of times they ate fruits in a day, were determined using the Chisquared one variable test; whereas the Binomial test was used for fruits availability on the market. Statistical significance was determined at the 5\% level $(\mathrm{P} \leq 0.05)$.

\section{RESULTS}

\section{Economic characteristics of participants}

Majority of the respondents $(64 \%, \mathrm{P}<0.05)$ indicated Ghana Cedi $(\mathrm{GH} 4) 5.00$ as the money available to them for their daily meals, whereas few of them ( $7.9 \%$ and $4.4 \%)$ indicated $\mathrm{GH} \overleftarrow{4} \leq 4.00$ and $\mathrm{GH} \mathbb{C} \geq 10.00$ respectively as their daily stipend for meals $(\mathrm{P}<0.05)$ (Table 1). 


\section{Cost of meals and fruits on the market}

Lowest price of meals (breakfast, lunch, or dinner) per plate was found to be GHष 1.00-1.55. That for fruits was found to be GHథ 0.20 per serving (Table 2).

\section{Factors that hinder fruit consumption}

The major factor that hindered the consumption of fruits by students is high price of fruits (economic variable) $(\overline{\mathrm{x}}=3.21, \mathrm{P}<0.05)$ and satiety $(\overline{\mathrm{x}}=3.32, \mathrm{P}<0.05)$, as most $(84 \%)$ of them were of the view that fruits are generally expensive on the market, per the GHథ 5.00 average daily stipend available to them for meals (Table 1) and the moderate cost of meals (per plate) and fruits (per serving) on the market (Table 2). On the subject of satiety, majority (87.5\%) attributed their irregular/low fruit intake to the fact that they do not get full when they eat fruits (Table 3). The following did not hinder the consumption of fruits by the students: time involved in eating fruits, knowledge about the importance of fruits in nutrition, participants belief/religion, ill health/health status, and taste of fruits $(\mathrm{P}<0.05)$ (Table 3$)$.

\section{Number of daily servings}

The study showed that most of the respondents (65\%) ate quantities below the 1992 USDA daily recommended serving of $2-4(\mathrm{P}<0.05)$. A significant number of students (approximately 6\%) did not eat fruits at all, while only $21.9 \%$ took a serving of fruits twice in a day $(\mathrm{P}<0.05)$ (Table 4$)$.

\section{Perception on fruit consumption}

The perception of the respondents on the consumption of fruits were found to be significantly positive as most of them ( $84.2 \%, 90.1 \%$, and $86.2 \%$ respectively) did not agree with the statements that fruits had no nutritional value and that only the rich, and white people are to eat fruits $(\mathrm{P}<0.05)$ (Table 5).

\section{Availability of fruits on the market for students}

With the exception of fruits such as guava, grapes, lime/lemon, passion fruits and others which were not commonly available on the market in the study area $(\mathrm{P}<0.05)$, the following fruits were available: orange $(\mathrm{n}=383, \mathrm{P}<0.05)$, apple $(\mathrm{n}=368$, $\mathrm{P}<0.05$ ), pineapple $(\mathrm{n}=366, \mathrm{P}<0.05)$, pawpaw $(\mathrm{n}=324, \mathrm{P}<0.05)$, banana $(\mathrm{n}=378$, $\mathrm{P}<0.05)$, mango( $\mathrm{n}=380, \mathrm{P}<0.05)$, pear $(\mathrm{n}=335, \mathrm{P}<0.05)$, tangerine $(\mathrm{n}=382$, $\mathrm{P}<0.05)$, and water melon $(\mathrm{n}=358, \mathrm{P}<0.05)$ (Table 6).

\section{Fruits most liked by students}

Fruits that were most preferred or frequently eaten by the respondents were (in decreasing order of preference): pear (Pyrus communis), tangerine (Citrus reticulata), apple (Malus domestica), banana (Musa acuminata), guava (Psidium guajava), watermelon (Citrullus lanatus), and pine apple (Ananas comosus). Oranges (Citrus sinensis) were the least preferred by the respondents $(\overline{\mathrm{x}}=2.31, \mathrm{P}<0.05)$ (Table 7).

\section{Association between fruit and fruit-fibre intake by students}

When correlation co-efficient values were computed to determine the respondents' level of preference for the juicy as well as the chewy-fibrous part of the fruits: orange (Citrus sinensis), tangerine (Citrus reticulata), and pine apple (Ananas comosus), a

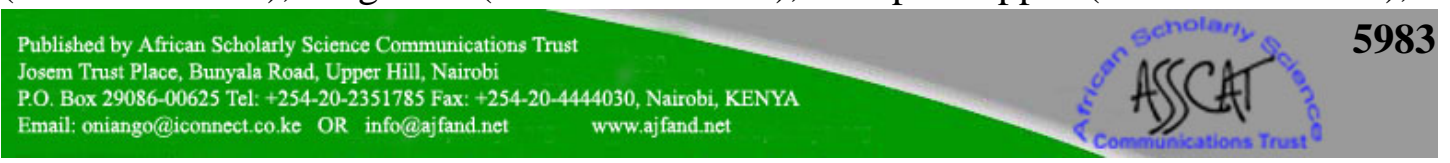


weak positive association was observed for how much respondents liked consuming the juicy part of tangerine, and the fibrous part of the fruit $(r=0.13, \mathrm{P}<0.05)$ (Table 8). Also, a weak negative relationship, which was statistically significant $(r=-0.14$, $\mathrm{P}<0.05$ ) was observed for the intake of oranges and its fibrous part (Table 8). There was also a weak positive association between respondents intake of the juicy part of pine apple and the fibrous part, but the association was not statistically significant $(r=$ $0.03, \mathrm{P}>0.05)$.

\section{DISCUSSION}

The study showed that although students in the study area had a positive perception about eating fruits, their daily intake was below the recommended daily serving of 24. This finding could be attributed to a link between how students perceived the price of fruits sold on the Ghanaian market and how full they become when they eat fruits. This follows the subjects' response that fruits sold on the market were expensive, and have low satiety value. This response was unexpected because if someone has a positive perception about fruits; it should rather motivate him/her to eat fruits despite the discouraging factors of price and satiety. From the study, comparing students' stipend for daily meals (Table 1) to the cost of fruits/meals (Table 2), it can be said that funds available to students was good enough to earn them at least two servings of fruit (GH4 0.40) in a day if they were to go for a moderate breakfast, lunch, and dinner that cost GH\$ 1.5 each. Better still, considering the positive perception that students had about eating fruits, one may possibly expect that they may go in for breakfast that cost GHष 1.00-1.40 and have a lunch and dinner that cost GHष 1.5 each. This will leave them with enough money (GH\$ 0.60-1.00) for 3-4 servings of fruits in a day. Implicit from this is that, the students' assertion that fruits are expensive on the market may not be completely true since their stipend for meals is good enough to earn them 3-4 servings of fruits per day. Instead, the cost variable may be linked to the satiety variable since majority $(87.5 \%)$ attributed their irregular/low fruit intake to the fact that they do not get full when they eat fruits (Table 3). The students, therefore, may have been looking at how the total cost of four servings of fruits could get them a plate of meal (with little cash top up) which will make them full rather than spending same sum on fruits. In that sense, fruits appear to be expensive.

In Eastern and Southern Europe, studies have shown that the consumption of fruits was more common among those with higher education [21]. Implicit from this observation is that even if price of fruits/satiety were to be a factor to hinder this group of people from eating fruits, they would still go ahead and eat fruits knowing the health and nutritional benefits they would derive from it. It follows, implicitly, that if they are made to choose between soft drinks and fruits, the group with higher educational background would choose fruits over soft drinks irrespective of the satiety they may derive from taking soft drinks. This is in contrast to the findings of this study involving students of higher learning institutions in Ghana. It is generally viewed that such students are in a better position in society to educate or encourage other people of low educational background about the benefits of eating fruits and eating the right serving per day, because the benefits derived from eating fruits

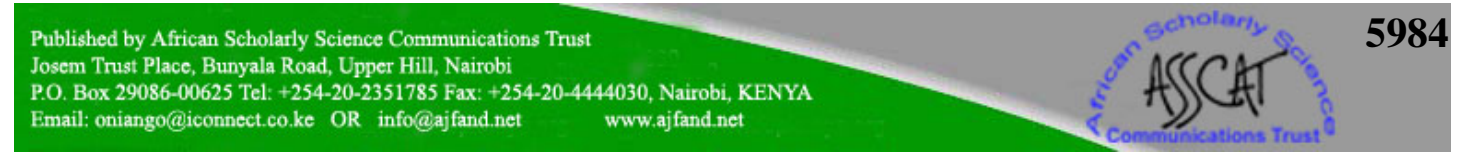


surpass the cost of the fruits. Another issue that arises out of this study is that a large portion of the respondents are more likely to develop chronic diseases such as coronary heart disease and some cancers with time from not eating enough fruits $[5,6$, 7].

The study also revealed that subjects consumed only the juicy or free water part of the fruits: tangerine (Citrus reticulata), pine apple (Ananas comosus) and orange (Citrus sinensis), without making effort to chew the fibrous (dietary fibre) part of these fruits. This means that the respondents did not fully gain all beneficial nutrients/nonnutrients from the fruits. The fruits (tangerine, pine apple, and orange) contain watersoluble fibres (pectin) and insoluble fibres (cellulose, hemicellulose and lignin) from which several health benefits are derived. Studies have shown that dietary fibre (water-soluble fibre) from fruits helps reduce blood cholesterol levels and may lower risk of heart disease. Also, fibre (insoluble fibre) from fruit is important for proper bowel function, helps reduce constipation and diverticulosis and provides a fill with fewer calories [8].

Contrary to previous studies carried out in Austria by Schätzer, Rust and Elmadfa, this study found that satiety as well as price constituted a relevant hindrance to fruit intake; and the intake of fruits can be estimated at one serving per day [27].

In conclusion, it is highly likely that the larger population of tertiary students consume less fruits than required and should be further enlightened on the importance of consuming fruits and eating the right serving each day irrespective of the cost of fruits on the local markets/ whether they get full or not in eating.

Also if people expected to be as enlightened as student at the tertiary level about the benefit of eating fruit are not doing what is required of them then what is happening in the larger population is left to anyone's imagination. Thus the entire populace of the nation should be included in the awareness creation process. The expected change in attitude towards eating fruits, achieved through awareness creation and education, would improve public health, and funds that would otherwise been spent on treating preventable diseases could be channelled into other areas of the economy. 


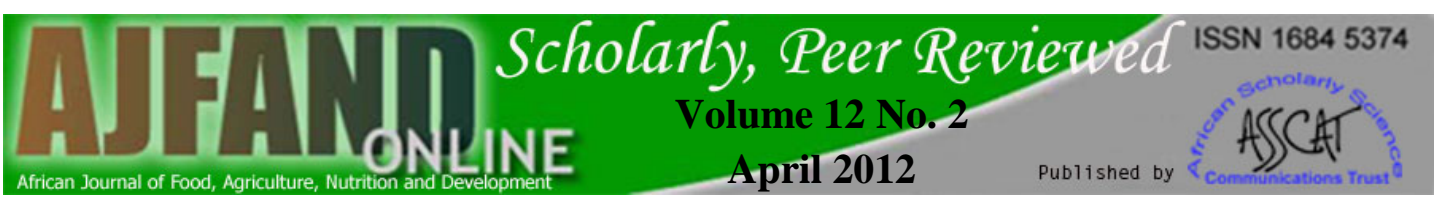

Table 1: Economic characteristics of participants

\begin{tabular}{|c|c|c|}
\hline $\begin{array}{l}\text { Funds (GHФ) available to } \\
\text { participants for their daily meals }\end{array}$ & Participants' response & Percentage response \\
\hline$\leq 4$ & 36 & $7.90 *$ \\
\hline 5 & 295 & $64.70^{*}$ \\
\hline 6 & 58 & $12.70 *$ \\
\hline 7 & 19 & $4.20 *$ \\
\hline 8 & 27 & $5.90 *$ \\
\hline 9 & 1 & $0.20 *$ \\
\hline 10 & 15 & $3.30 *$ \\
\hline$\geq 11$ & 5 & $1.10^{*}$ \\
\hline Total & 456 & 100 \\
\hline
\end{tabular}

* = significant at $\mathrm{P} \leq 0.05$ 


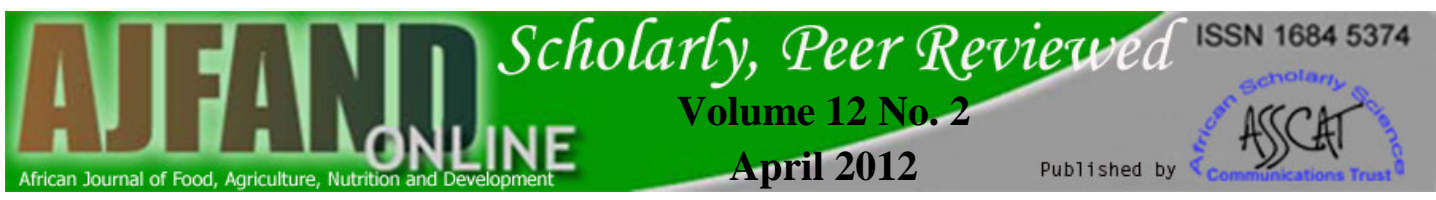

Table 2: Price of meals/ fruits sold on the market

\begin{tabular}{lll}
\hline \multirow{2}{*}{$\begin{array}{l}\text { Meal (per plate)/ fruit (per } \\
\text { serving) }\end{array}$} & \multicolumn{2}{c}{ Price (GHФ) } \\
\cline { 2 - 3 } & Lowest & Highest \\
\hline Breakfast & $1.00(0.90)$ & $3.02(0.24)$ \\
Lunch & $1.53(0.29)$ & $5.02(0.27)$ \\
Dinner & $1.55(0.49)$ & $5.01(0.23)$ \\
Snack & $1.00(0.03)$ & $1.79(0.04)$ \\
Fruit & $0.20(0.01)$ & $0.50(0.01)$
\end{tabular}

Values are mean amount in Ghana Cedi (GHథ), ( ) = standard deviation. 


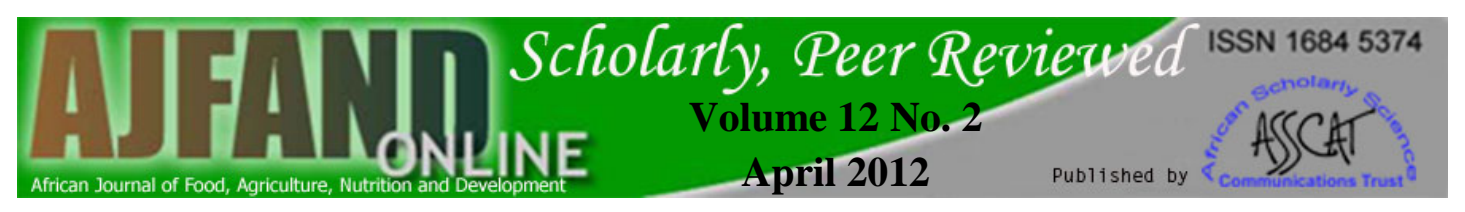

Table 3: Factor(s) that prevented respondents from eating fruits

Factor(s) Percent likert response

MR SD

\begin{tabular}{llll}
\hline 4 & 3 & 2 & 1
\end{tabular}

- I do not eat fruits regularly because they are generally expensive on the market

41.90

42.10

11.6

4.40

$3.21 * 0.89$

- I do not eat fruits regularly because it is time consuming

$\begin{array}{llllll}2.90 & 30.70 & 44.30 & 22.10 & 2.14 * & 0.79\end{array}$

- I do not eat fruits regularly because they do not have any nutritional value

$\begin{array}{llllll}2.20 & 26.30 & 3.50 & 68.00 & 1.63 * & 0.94\end{array}$

- My belief/ religion does not allow me to eat fruits

$\begin{array}{llllll}0.00 & 6.10 & 6.10 & 87.7 & 1.18 * & 0.52\end{array}$

- I do not eat fruits because of ill health

$\begin{array}{llllll}0.90 & 6.60 & 6.60 & 86.00 & 1.22 * & 0.60\end{array}$

- I do not eat fruits regularly because I don't like the taste

- I do not eat fruits regularly because they do not make me full

$\begin{array}{llllll}44.50 & 43.00 & 12.10 & 0.40 & 3.32 * & 0.69\end{array}$

$\mathrm{MR}=$ mean response, $\mathrm{SD}=$ standard deviation, $4=$ strongly agree, $3=$ Agree, $2=$ Disagree, $1=$ strongly disagree, $*=$ significant at $\mathrm{P} \leq 0.05$ 


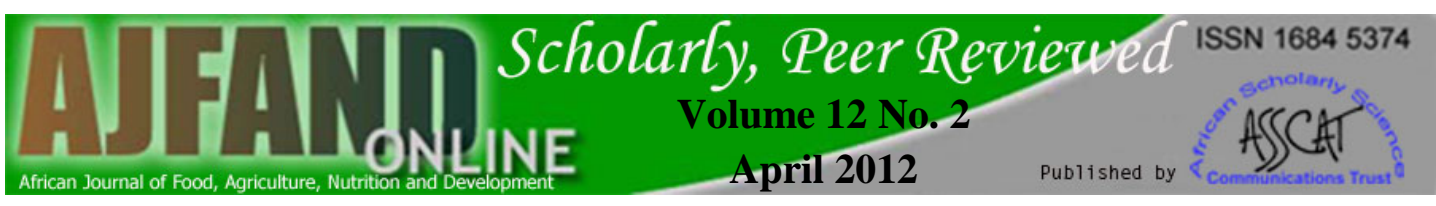

Table 4: Number of times respondents ate a serving of fruits in a day

\begin{tabular}{lcc}
\hline Number & Participants response & Percentage response \\
\hline None & $26^{*}$ & 5.7 \\
Once & $298^{*}$ & 65.4 \\
Twice & $100^{*}$ & 21.9 \\
Thrice & $26^{*}$ & 5.7 \\
Four times & $4 *$ & 0.9 \\
Five times & $2 *$ & 0.4 \\
\hline Total & 456 & 100.0 \\
\hline
\end{tabular}

$*$ = significant at $\mathrm{P} \leq 0.05$

Table 5: Perception of respondents on eating fruits

\begin{tabular}{|c|c|c|c|c|c|c|}
\hline \multirow[t]{2}{*}{ Perception } & \multicolumn{4}{|c|}{ Percent likert response } & \multirow[t]{2}{*}{ MR } & \multirow[t]{2}{*}{ SD } \\
\hline & 4 & 3 & 2 & 1 & & \\
\hline $\begin{array}{l}\text { - Fruits are food for the rich } \\
\text { - Fruits are food for the whites/ wl }\end{array}$ & 3.70 & 6.10 & 20.40 & 69.70 & $1.44^{*}$ & 0.77 \\
\hline and women & 8.10 & 5.70 & 27.4 & 58.80 & $1.63^{*}$ & 0.91 \\
\hline - Fruits have no nutritional value & 8.80 & 7.00 & 32.90 & 51.30 & $1.73^{*}$ & 0.93 \\
\hline
\end{tabular}

$\mathrm{MR}=$ mean response, $\mathrm{SD}=$ standard deviation, $4=$ strongly agree, $3=$ Agree, $2=$ Disagree, $1=$ strongly disagree, $*=$ significant at $\mathrm{P} \leq 0.05$ 


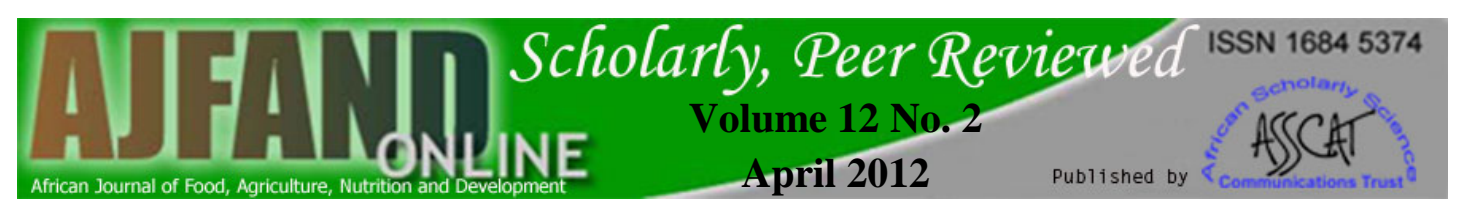

Table 6: Fruits available on the market for students

\begin{tabular}{|c|c|c|c|}
\hline \multirow{2}{*}{$\begin{array}{l}\text { Fruits } \\
\text { (Common name) }\end{array}$} & \multirow[t]{2}{*}{ Fruits (Scientific name) } & \multicolumn{2}{|c|}{ Participants' response } \\
\hline & & Available & Un-available \\
\hline Blackberries & Rubus fruticosus & $44^{\mathrm{b}}$ & $412^{a}$ \\
\hline Grape fruit & Citrus paradise & $195^{\mathrm{a}}$ & $261^{b}$ \\
\hline Tangerine & Citrus reticulata & $382^{b}$ & $74^{\mathrm{a}}$ \\
\hline Cantaloupe & Cucumis melo & $9^{\mathrm{a}}$ & $447^{\mathrm{b}}$ \\
\hline Strawberries & Fragaria ananassa & $16^{\mathrm{b}}$ & $440^{\mathrm{a}}$ \\
\hline Orange & Citrus sinensis & $383^{a}$ & $73^{b}$ \\
\hline Apple & Malus domestica & $368^{b}$ & $88^{a}$ \\
\hline Banana & Musa acuminata & $378^{a}$ & $78^{b}$ \\
\hline Peach & Prunus persica & $22^{b}$ & $434^{\mathrm{a}}$ \\
\hline Pear & Pyrus communis & $335^{a}$ & $121^{\mathrm{b}}$ \\
\hline Apricot & Prunus armeniaca & $9^{b}$ & $447^{\mathrm{a}}$ \\
\hline Pine apple & Ananas comosus & $366^{\mathrm{a}}$ & $90^{\mathrm{b}}$ \\
\hline Water melon & Citrullus lanatus & $358^{b}$ & $98^{\mathrm{a}}$ \\
\hline Mango & Mangifera indica & $380^{\mathrm{a}}$ & $76^{b}$ \\
\hline Pawpaw & Carica papaya & $324^{\mathrm{b}}$ & $132^{\mathrm{a}}$ \\
\hline Guava & Psidium guajava & $288^{\mathrm{a}}$ & $288^{\mathrm{a}}$ \\
\hline Grapes & Vitis vinifera & $10^{\mathrm{a}}$ & $448^{b}$ \\
\hline Lime/lemon & $\begin{array}{l}\text { Citrus aurantiifolia/ Citrus } \\
\text { limon }\end{array}$ & $196^{\mathrm{a}}$ & $260^{b}$ \\
\hline Passion fruit & Passiflora edulis & $56^{\mathrm{a}}$ & $400^{b}$ \\
\hline
\end{tabular}

Values are total number of respondents; values on same row with different letter as superscripts are significantly different $(\mathrm{P} \leq 0.05)$ 


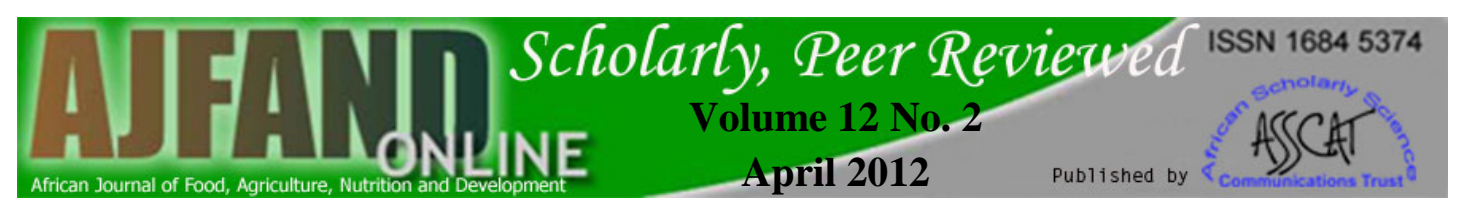

Table 7: Fruits most liked by respondents

\begin{tabular}{|c|c|c|c|c|c|c|}
\hline \multirow[t]{2}{*}{ Fruit(s) } & \multicolumn{4}{|c|}{ Percent likert response } & \multirow[t]{2}{*}{ MR } & \multirow[t]{2}{*}{ SD } \\
\hline & 4 & 3 & 2 & 1 & & \\
\hline Citrus sinensis & 9.40 & 35.50 & 32.00 & 23.00 & $2.31 *$ & 0.93 \\
\hline Malus domestica & 38.60 & 37.50 & 22.10 & 1.80 & $3.13 *$ & 0.81 \\
\hline Ananas comosus & 29.40 & 46.50 & 20.00 & 4.20 & $3.01 *$ & 0.81 \\
\hline Carica papaya & 24.30 & 51.50 & 20.00 & 4.20 & $2.96 *$ & 0.78 \\
\hline Psidium guajava & 36.80 & 39.00 & 20.60 & 3.50 & $3.09 *$ & 0.84 \\
\hline Musa acuminata & 38.60 & 37.50 & 20.40 & 3.50 & $3.11 *$ & 0.85 \\
\hline Mangifera indica & 23.50 & 52.40 & 20.00 & 4.20 & $2.95 *$ & 0.77 \\
\hline Pyrus communis & 49.60 & 38.40 & 11.80 & 0.20 & $3.37 *$ & 0.70 \\
\hline Citrus reticulata & 43.20 & 39.50 & 15.60 & 1.80 & $3.24 *$ & 0.77 \\
\hline Citrullus lanatus & 35.70 & 40.10 & 20.60 & 3.50 & $3.08 *$ & 0.84 \\
\hline
\end{tabular}

Table 8: Association between intake of juicy, and fibrous parts of fruit

\begin{tabular}{llll}
\hline Fruit(s) & $\begin{array}{l}\text { Mean preference/ } \\
\text { intake }\end{array}$ & Mean fibre intake & $\begin{array}{l}\text { Correlation co- } \\
\text { efficient }(r)\end{array}$ \\
\hline Citrus sinensis & 2.31 & 1.25 & $-0.14^{* *}$ \\
Ananas comosus & 3.01 & 1.23 & 0.03 \\
Citrus reticulata & 3.24 & 2.25 & $0.13^{* *}$ \\
\hline
\end{tabular}

$* *=$ significant at $\mathrm{P} \leq 0.0005$ 


\section{REFERENCES}

1. Mauseth JD Botany: an introduction to plant Biology. Jones and Bartlett, Massachusetts. 2003: 271-72.

2. Schlegel RHJ Encyclopaedic dictionary of plant breeding and related subjects. Haworth Press, New York. 2003:177.

3. Lewis RA CRC Dictionary of Agricultural Science. CRC Press, Florida. 2002: 172-98.

4. Kyaw KT and E Barret-Cannor Dietary potassium and stroke-associated mortality; a 12 year prospective population study. Engl. J. Med. 1987; 3116: 236-39.

5. Tribble DL Antioxidant consumption and risk of coronary heart disease, emphasis on vitamin $\mathrm{C}$, vitamin $\mathrm{E}$ and beta-carotene; a statement for health care professionals from the American Heart Association. Circulation. 1999; 99: 591-595.

6. Ness AR and JW Powles Fruit and vegetable and cardiovascular disease: a review. Int. J. Epidemiol.1997; 26: 1-12.

7. Law MR and JK Morris By how much does fruit and vegetable consumption reduce the risk of ischemic heart disease? Eur. J. Clin. Nutr. 1998; 52: 549553.

8. USDA. Why is it important to eat fruit? http://www.mypyramid.gov/ pyramid/fruits_why.html. Accessed 10/10/2009.

9. Everything you want to know about fruits. http://www.thefruitpage.com/. Accessed 21/2/2009.

10. Ridgewell $\mathbf{J}$ Examining food and nutrition. Oxford University Press, London. 1998: 58.

11. Hall JN, Moore S, Harper SB and JW Lynch Global variability in fruit and vegetable consumption. Am. J. Preventive Med. 2009; 36(5):402-409.

12. Douglas L Children’s food choices. Nutri. Food Sci. 1998; 1:14-8.

13. Johnson B and AF Hacket Eating habits of 11-14 year-old school children living in less affluent areas of Liverpool, UK. J. Human Nutri. Diet. 1997; 10: 37-51. 
14. Noble C, Corney M, Eves A, Kipp $\mathbf{M}$ and $\mathbf{M}$ Lumbers Food choices and school meals: primary school children's perceptions of the healthiness of foods and the nutritional implications of food choices. Int. J. Hosp. Management 2000; 19:413-432.

15. Noble C, Corney M, Eves A, Kipp M and M Lumbers Food choices and secondary school meals: the nutritional implications of choices based on preference rather than perceived healthiness. Int. J. Hosp. Management 2003; 22:197-215.

16. Vaclavick VA and EW Christian Essentials of food science. Kluwer Academic Publishers, New York. 2003: 96-114.

17. USDA. The improved American food guide pyramid. http://www. absoluteastronomy.com/topics/Food_guide_pyramid. Accessed 10/11/2009.

18. Havas S, Heimendinger J, Reynolds K, Baranowski T, NicklasTA, Bishop D, Buller D, Sorensen G, Beresford SA and A Cowan 5 a day for better health: a new research initiative. J. Am. Diet. Assoc. 1994; 94: 32-6.

19. Tetens I 6 a day - development project. Scand. J. Nutri. 1999; 43: 176.

20. Medical News Today Most of us are not eating enough fruits and vegetables. http://www.medicalnewstoday.com/articles/. Accessed 5/8.2009.

21. Roos G, Johansson L, Kasmel A, Klumbiene J and R Prättälä Disparities in vegetable and fruit consumption: European cases from the north to the south. Pub Health Nutr. 2000; 4(1): 35-43.

22. Ghana News Agency (GNA). Low intake of fruits and vegetables causes heart diseases and cancer. November 12, 2003. http://www.mordenghana. com/news/44342/1/lowintake-of-fruits-and-vegetables-cause-heart-di.html.

Accessed 10/11/2009.

23. Shah S Flowering plants and trees. In: Marshall A, Carpenter C and S MacFall (Eds) Guinness book of knowledge. New York: Guinness Media Inc, 1997: 65.

24. Gaman PM and KB Sherrington Vitamins: the science of food. Reed Educational and Professional Publishing Ltd, Jordan Hill. 1996: 68-211.

25. Pyke M Catering science and technology. John Murray Publishers, London. 1974: 29-39.

26. Sarantakos S Social research. MacMillan, New York. 2005: 170-172.

27. Schätzer M, Rust $\mathbf{P}$ and I Elmadfa Fruit and vegetable intake in Austrian adults: intake frequency, serving sizes, reasons for and barriers to consumption, and potential for increasing consumption. Pub Health Nutri. 2010; 13(4): 480-487. 